\title{
Patient self-determination act of Taiwan
}

\begin{abstract}
Medical teams often face the dilemma either to rescue the life of the patients whose conditions are beyond remedy yet the family members insist doctors to keep the patients alive to wait for miracle. Old tradition regards those trying their best to make longevity of their elderly possible is a filial act. In order to give patients a right to choose how they will be treated, a new act called Patient Self-determination Act was introduced and passed in 2015 that is to be effective in 2018. This short article will introduce what this is act is all about.
\end{abstract}

Volume 2 Issue 5 - 2018

\author{
Michael Cheng-tek Tai \\ Chungshan Medical University, Taiwan \\ Correspondence: Michael Cheng-tek Tai, Chair professor, \\ Chungshan Medical University, Taiwan, \\ Email mclaicht@gmail.com
}

Received: April 04, 20I8 | Published: October 29, 2018

\section{Introduction}

\section{Taiwan's patient self-determination act}

Does a person have a right to choose the kind of treatment he or she prefers when incurable illness has been diagnosed? The traditional culture in Taiwan regards longevity as one of goals of life therefore children will try their best to prolong the life of their elderly as long as possible to show that they are filial sons. As a result many futile treatments have repeatedly attempted that prolonged the suffering of the terminal patients. To respond to this waste of medical resources and to uphold the dignity of life to end without unnecessary pain, Taiwan parliament has adopted a new legislation in Dec 18, 2015 called Patient Self-determination Act that is to take effect in 2018. This act will allow patients the right to direct their wish when facing the incurable diseases or suffering from uncontrollable pain. This new legislation was initiated by a physically disabled legislator named Yang Yu-hsin who was confined to a wheelchair since 19 year of age due to a muscle disorder. This rare disease is caused by gene mutation that also crippled her two other siblings. Yang said the act is about the dignity and autonomy of human beings. ${ }^{1}$

The purpose of this act is to emphasize the importance of patients' rights when it comes to medical decision making, especially when it is about a matter of life or death. Because of this Act, patients can make their own Advance Directive by stating whether they wish to accept or refuse any kind of medical treatments when diagnosed with the following conditions: being terminally-ill, in a coma or persistent vegetative state, or with advanced dementia or incurable diseases that include unbearable pain. ${ }^{2}$

If any patient belonging to one of these categories can sign a directive to be witnessed by two fully capable adults and notarised then to be registered in the National Health Insurance system. In the process, two specialist physicians are required to confirm that the concerned patient meets on of the five conditions stated in the act. An immunity is also introduced to free medical institutions and physicians from being persecuted when suspending, removing or refusing life sustaining treatments according to the patients' Advance Directive. In the case when patients and family members hold different opinions, this act allows the medical institution and staff to focus on the patients' will and prevents family members from interfering.

The Taiwan Hospice Organization called this Act a major step forward in respecting patient's autonomy to end the suffering. ${ }^{2}$ For the first time those terminally ill, in coma, vegetative state, or with advanced dementia or incurable diseases are allowed to express their wish either to accept or deny medical treatment. As stated above, to have a valid directive, patients must be required to be consulted by medical specialists to ensure their consciousness and comprehension.
This act is by no means euthanasia, rather, it gives the patients a right to say no to a futile treatment that prolongs the painful death process.

This act does not mean those who sign the document will be abandoned by the medical team. Taiwan has a very solid hospice program to care for those who receive no more active medical procedures to ensure them a peaceful way of resting into eternity, if so requested.

\section{The hospice care in Taiwan}

Every major hospital in Taiwan is required to have a palliative care unit that provides hospice. An association of hospital hospice whose members come from all teaching hospitals had been established in 1990. Any individual willing to promote and share the philosophy of hospice can also become a member. In Taiwan, besides government sponsored hospitals, there are also hospitals established by the religious groups and the business sectors. This association is transdenominational and trans-religious including all the Protestant, Catholic, Buddhist, Taoist, veteran and general hospitals that are funded by the governments. All hospitals adopt the model of C. Saunders' hospice philosophy and program to give total cares that are physical, social, psychological, spiritual and familial in dimensions. The goal of this end of life care is to make sure every patient will pass on with support, comfort and dignity without too much pain. If patient has any unfinished business or dispute or broken relationship with family members, the hospice teams will assist to make sure the reconciliation is reached before the last breath. We can say Taiwan's end of life care aims at giving each dying person a worry-free death, so to speak.

\section{Final words}

Death is a human common destination, it should come not as a painful thing but a natural process that people confront with ease and courage. Taiwan's Patient Self-determination Act shows each person owns the right to choose how he or she is going to end lives without meaningless suffering.

\section{Acknowledgements}

None.

\section{Conflict of interest}

The authors declare there is no conflict of interest.

\section{References}

1. The webpages of the Legislative Yuan. Taiwan; 2018.

2. The webpages of Ministry of Health and Welfare. Taiwan; 2018. 